\title{
Clinical Features of 2009 Pandemic Infuenza A (H1N1) Virus Infection in Chronic Hemodialysis Patients
}

\author{
Han Li Shi-xiang Wang \\ Blood Purification Center, Beijing Chao-Yang Hospital, Capital Medical University, Beijing, China
}

\section{Key Words}

H1N1 virus infection $\cdot$ Renal dialysis $\cdot$ Clinical features

\begin{abstract}
Background/Aims: Infection is one of the most common complications and is considered the second leading cause of death in dialysis patients with end-stage renal disease. After the first cases of 2009 pandemic influenza A (H1N1) virus in China became public, persons with suspected infection and those who were in contact with persons with suspected infection were tested. Whether the presentation and clinical course of H1N1 influenza is similar in the dialysis population to the general population is currently unknown. Hemodialysis patients in whom an infection was confirmed were hospitalized and quarantined, and patients on chronic hemodialysis were closely observed for the purpose of investigating the nature and duration of the disease. Methods: From May 2009 to February 2010, we observed 15 hemodialysis patients infected with the 2009 pandemic influenza A (H1N1) virus who were quarantined in Beijing Chao-Yang Hospital, Capital Medical University. Real-time reverse transcriptase polymerase chain reaction (RT-PCR) testing was used to confirm infection, the clinical features of the disease were closely monitored. Results: The mean age of the 15 patients was
\end{abstract}

47.6 years, and 9 of the 15 patients were male. The diagnoses were all made in the hospital. All of the 15 patients had fluid overload. The median incubation period of the virus in hemodialysis patients was 4 days (range: 1-7 days). The most common symptoms were dyspnea (in all of the 15 patients) and productive cough (in all of the 15 patients). One of the 15 patients had low-grade fever, and the other 14 patients were afebrile. Lymphopenia, which was common in 12 of the patients, typically occurred on day 2 (range: days 1-3) and resolved by day 9 (range: days 7-11). Hypoxemia was observed in all of the patients. Six of the 15 patients developed respiratory failure requiring mechanical ventilation on days 7-9 because they were complicated by Escherichia coli nosocomial pneumonia. All the patients were placed in respiratory isolation and were treated with oseltamivir. The median length of time during which patients had positive real-time RT-PCR test results was 12 days (range: 7-19 days), which was longer than that in general population. Conclusions: The presentation and clinical course of H1N1 influenza $A$ in the hemodialysis patients was atypical and relatively serious, which differed from the general population in China. Furthermore, these patients may have an extended period of viral shedding.

Copyright $\odot 2010$ S. Karger AG, Basel

\section{KARGER}

Fax +4161306 1234 E-Mail karger@karger.ch www.karger.com
(C) 2010 S. Karger AG, Basel

0253-5068/10/0303-0172\$26.00/0

Accessible online at:

www.karger.com/bpu
Shi-xiang Wang

Blood Purification Center, Beijing Chao-Yang Hospital

Capital Medical University, No. 8 Gongti South Road

Beijing 100020 (China)

Tel./Fax +86 106593 5007, E-Mail wxy1988@263.net 


\section{Introduction}

The $2009 \mathrm{H} 1 \mathrm{~N} 1$ virus is a triple-reassortant influenza virus containing genes from human, porcine and avian influenza viruses [1-3]. In early April 2009, cases of human infection with the 2009 pandemic influenza A (H1N1) virus were identified in the USA $[4,5]$ and Mexico [6], and the virus then spread rapidly to other regions of the world $[7,8]$. The first 3 cases of confirmed infection with the virus in the general population in China were documented between May 10 and May 15, 2009 [9]. After documentation of human-to-human transmission of the virus in at least 3 countries in 2 of the 6 world regions defined by the World Health Organization (WHO), the WHO raised the pandemic level from 5 to 6 , the highest level [10].

The 2009 pandemic influenza A (H1N1) virus can occur in both healthy individuals and those with chronic illness including end-stage renal failure. Whether the presentation and clinical course of H1N1 influenza is similar in the dialysis population to the general population is currently unknown. Clinical information about the effect of the 2009 pandemic influenza A (H1N1) virus on hemodialysis patients is lacking in China. This report describes the clinical and epidemiologic characteristics of the hemodialysis patients hospitalized in Beijing ChaoYang Hospital, Capital Medical University, from May 2009 to February 2010 with confirmed cases of 2009 pandemic influenza A (H1N1) virus infection.

\section{Methods}

\section{Data Sources}

On May 7, 2009, a national network was organized to monitor infection with the 2009 pandemic influenza A (H1N1) virus in China.

The network included the Chinese Ministry of Health, the Chinese Center for Disease Control and Prevention, and all community and teaching hospitals in China. A national guideline, adapted from guidelines provided by the US Centers for Disease Control and Prevention, was published on May 9 and used to direct the surveillance, reporting, diagnosis and treatment of the disease.

A suspected case was defined as an influenza-like illness (temperature of $\geq 37.5^{\circ} \mathrm{C}$ and at least 1 of the following symptoms: sore throat, cough, rhinorrhea or nasal congestion) and either a history of travel to a country where infection had been reported in the previous 7 days or an epidemiologic link to a person with confirmed or suspected infection in the previous 7 days. A confirmed case was defined by a positive result by real-time reverse transcriptase polymerase chain reaction (RT-PCR) assay performed at a laboratory operated under the auspices of the Chinese Center for Disease Control and Prevention. A close contact was defined as a person who lived with or was exposed to the respiratory secretions or other bodily fluids of someone with suspected or confirmed infection.

Thermal scanners were installed at the entrance to our blood purification center. There were 226 chronic hemodialysis patients in our unit. Hemodialysis patients suspected of being infected and persons identified as close contacts were quarantined for 7 days, during which time pharyngeal or nasopharyngeal swabs were collected for detection of the virus by means of a realtime RT-PCR assay. The average time between obtaining the samples and testing was $1-2 \mathrm{~h}$. The laboratory is operated by the Chinese Center for Disease Control and Prevention across China, which is located in Beijing Chao-Yang Hospital, Beijing Institute of Respiratory Medicine, Capital Medical University. Hemodialysis patients with confirmed infection were admitted to the infectious diseases department, where they could be quarantined.

The incubation period was defined as the time from exposure to the onset of illness. Patients were followed until discharge, with symptoms and signs recorded daily. The details of all investigations and treatments were recorded. Serial pharyngeal or nasopharyngeal swabs were analyzed daily for the presence of 2009 pandemic influenza A (H1N1) virus by the use of real-time RTPCR testing. A return to normal body temperature was defined as a temperature of less than $37.3^{\circ} \mathrm{C}$ for $12 \mathrm{~h}$ after the withdrawal of any antipyretic treatment. The criteria for discharge or removal from isolation (as defined in the guideline) were 2 readings of normal body temperature taken on 2 consecutive days, the absence of respiratory symptoms, and negative results on the testing of samples from 2 consecutive pharyngeal or nasopharyngeal swabs. The study was approved by the ethics committee of Beijing Chao-Yang Hospital affiliated to Capital Medical University, and written informed consent was obtained from each patient.

Laboratory Confirmation of Infection

The 2009 H1N1 virus was detected by the use of a real-time RT-PCR assay in accordance with the protocol from the US Centers for Disease Control and Prevention, as recommended by the WHO [11]. The PCR products were sequenced for further confirmation by the use of the BigDye Terminator, version 3.1, Cycle Sequencing Kit (Applied Biosystems) in accordance with the manufacturer's instructions.

\section{Statistical Analysis}

Statistical analysis was performed by SPSS for Windows version 13.0. Continuous variables were summarized as means $\pm \mathrm{SD}$ or medians (with full ranges). For categorical variables, the percentages of patients in each category were calculated. Clinical characteristics were compared between patients with and those without hemodialysis by the use of a one-sample t test, as appropriate (the respective data on nonhemodialysis patients have been published elsewhere [12]). $\mathrm{p}<0.05$ was considered to indicate statistical significance. 
Table 1. Characteristics, underlying medical conditions and outcomes of 15 hemodialysis patients infected with 2009 pandemic influenza A (H1N1) virus in China (May 2009 to February 2010)

\begin{tabular}{lc}
\hline Male sex, $\mathrm{n}$ & 9 \\
Age, years & \\
$\quad$ Mean \pm SD & $47.6 \pm 22.0$ \\
$\quad$ Range & $25-81$ \\
Coexisting conditions, $\mathrm{n}$ & 15 \\
$\quad$ Volume overload & 12 \\
$\quad$ Hypertension & 9 \\
$\quad$ Congestive heart failure & 9 \\
$\quad$ Left ventricle systolic function insufficiency & \\
Incubation period, days & 4 \\
$\quad$ Median & $1-7$ \\
$\quad$ Range & \\
Exposure site, n/total n & $3 / 15$ \\
$\quad$ Home & $12 / 15$ \\
$\quad$ Hospital & 12 \\
Viral shedding verified by real-time RT-PCR testing, $\mathrm{n}$ \\
$\quad$ Median & $7-19$ \\
$\quad$ Range & \\
\hline
\end{tabular}

\section{Results}

\section{Demographic and Clinical Characteristics of}

Hemodialysis Patients

A total of 9 male and 6 female chronic hemodialysis patients were included from May 2009 to February 2010. Their mean duration of hemodialysis was 28.8 months (range: 3-120 months). Nine patients developed endstage renal failure as a result of chronic glomerulonephritis, 3 from obstructive nephropathy, and 3 from an unknown cause. The characteristics, underlying medical conditions and outcomes of the 15 hemodialysis patients infected with the 2009 pandemic influenza A (H1N1) virus are listed in table 1.

The median incubation period of the virus in hemodialysis patients was 4 days (range: 1-7 days), which was significantly longer than that in patients without hemodialysis (the median incubation period of the virus in general patients was 2 days [12]; $\mathrm{t}=3.742$; $\mathrm{p}=0.002$ ). As shown in table 2 , the most common symptoms were dyspnea (in all of the 15 patients) and productive cough (in all of the 15 patients). One of the 15 patients had lowgrade fever, but the other 14 patients were afebrile.

\section{Laboratory and Radiographic Findings}

Mild leukopenia was observed in 3 of the 15 hemodialysis patients, and lymphopenia in 12 of the 15 hemodialysis patients, typically occurring on day 2 (range: days
Table 2. Clinical features at presentation

\begin{tabular}{|c|c|c|}
\hline & $\begin{array}{l}\text { Present at } \\
\text { admission, } \mathrm{n}\end{array}$ & $\begin{array}{l}\text { Duration } \\
\text { days }\end{array}$ \\
\hline \multicolumn{3}{|l|}{ Symptoms } \\
\hline \multicolumn{3}{|l|}{ Elevated temperature } \\
\hline $37.3-38.0^{\circ} \mathrm{C}$ & $1 / 15(6.7)$ & 1 \\
\hline$>38.0^{\circ} \mathrm{C}$ & $0 / 15(0)$ & \\
\hline Cough & $15 / 15(100)$ & $7(5-12)$ \\
\hline Sputum production & $15 / 15(100)$ & $5(4-10)$ \\
\hline White sputum & $9 / 15(60)$ & NA \\
\hline Yellow sputum & $6 / 15(40)$ & NA \\
\hline Sore throat & $0 / 15(0)$ & \\
\hline Dyspnea & $15 / 15(100)$ & $5(3-7)$ \\
\hline Rhinorrhea & $0 / 15(0)$ & \\
\hline Headache & $0 / 15(0)$ & \\
\hline Nasal congestion & $0 / 15(0)$ & \\
\hline Fatigue & $0 / 15(0)$ & \\
\hline Myalgia/arthralgia & $0 / 15(0)$ & \\
\hline Chill & $0 / 15(0)$ & \\
\hline Conjunctival congestion & $0 / 15(0)$ & \\
\hline Diarrhea & $0 / 15(0)$ & \\
\hline Nausea/vomiting & $0 / 15(0)$ & \\
\hline Chest pain & $0 / 15(0)$ & \\
\hline \multicolumn{3}{|l|}{ Signs } \\
\hline Rales in the lungs & $15 / 15(100)$ & $5(4-8)$ \\
\hline Congestion of throat & $0 / 15(0)$ & \\
\hline Swelling of tonsils & $0 / 15(0)$ & \\
\hline Enlargement of lymph nodes & $0 / 15(0)$ & \\
\hline Mechanical ventilation & $6 / 15(40)$ & $3(2-3)$ \\
\hline Hospital length of stay & & $14(9-23)$ \\
\hline
\end{tabular}

Values are numbers with percentages in parentheses or medians with ranges in parentheses. NA = Not available.

1-3) and resolving by day 9 (range: days 7-11). All of the 15 hemodialysis patients had an abnormal CD4:CD8 ratio (less than 1.4). Hypoxemia was observed in all of the patients, whose oxygen saturation was $93-95 \%$ with supplemental oxygen. The most common features observed by chest radiography at admission were bilateral airspace opacification, vascular redistribution and local patchy shadowing.

\section{Clinical Outcomes}

All of the 15 hemodialysis patients infected with the 2009 pandemic influenza A (H1N1) virus were placed in respiratory isolation and were treated with a reduced dose of oseltamivir. Six of the 15 patients developed respiratory failure requiring mechanical ventilation on days 7-9 because their infections were complicated by Escherichia 
coli nosocomial pneumonia. The median hospital length of stay of the 15 chronic hemodialysis patients was 14 days (range: 9-23 days). Finally, all of the 15 hemodialysis patients were discharged home.

The results from the serial virologic testing of samples from pharyngeal or nasopharyngeal swabs by the use of real-time RT-PCR were available for the 15 hemodialysis patients. The median length of time during which patients had positive real-time RT-PCR test results was 12 days (range: 7-19 days), which was longer than that in the general population (the median length of time during which general patients had positive real-time RT-PCR test results was 6 days [12]; $t=5.684 ; \mathrm{p}=0.000$ ).

After having been diagnosed with $\mathrm{H} 1 \mathrm{~N} 1$ infection, all of the 15 patients were hemodialyzed in an isolated and separately ventilated area within the dialysis facility. The hemodialyzers were not reused. Both the hemodialysis patients with H1N1 infection and the dialysis unit staff wore gauze masks and hats. No H1N1 cases were infected within our hemodialysis unit. No adverse events occurred in the 15 hemodialysis patients, who were taking oseltamivir.

\section{Discussion}

In this case series, we described the clinical course of 15 chronic hemodialysis patients who contracted the 2009 pandemic influenza A (H1N1) virus between May 2009 and February 2010. Since July 10, 2009, hospitalization for the purpose of isolation has not been mandated in China. Public health measures have instead focused on managing clusters of infection and complications of the illness in certain patients. As of December 20, 2009, more than 208 countries and overseas territories or communities worldwide have reported laboratory-confirmed cases of 2009 pandemic influenza A (H1N1) virus, including at least 11,516 deaths [13]. Whether the presentation and clinical course of H1N1 influenza is similar in the hemodialysis population to the general population is currently unknown.

To date, it has been difficult to define the true incubation period of the virus $[6,14-16]$. An analysis of 125 cases from China [12] suggested that the median incubation period was 2 days, with a range of 1-7 days in the general population. Close observation of the 15 confirmed infections in hemodialysis patients in China provided the opportunity to investigate the incubation period with an exact date of onset of illness. The median incubation period of H1N1 influenza in the hemodialysis population was 4 days, with a range of 1-7 days. The median length of time during which the hemodialysis patients had positive real-time RT-PCR test results was 12 days (range: 7-19 days), which was different from the general population [12] infected with the 2009 pandemic influenza A (H1N1) virus.

Observation of these 15 cases suggests that the presentation in chronic hemodialysis patients may differ; most H1N1 influenza cases meet the definition of influenzalike illness of fever plus cough or sore throat [17] - this did not transpire in 15 of our hemodialysis patients. As compared with general patients infected with H1N1 in China [12], fewer patients on hemodialysis presented with fever. The most common symptoms were dyspnea, productive cough and hypoxemia. In our cohort, 3 of the 15 hemodialysis patients had leukopenia (white cell count: $<4,000 / \mathrm{mm}^{3}$ ), and 12 of the 15 hemodialysis patients had lymphopenia (total lymphocyte count: $<1,500$ / $\mathrm{mm}^{3}$ in adults). None of the hemodialysis patients had thrombocytopenia (total platelet count: $<100,000 / \mathrm{mm}^{3}$ ). The lymphopenia was transient. Both leukocytosis and leukopenia were reported in hospitalized patients in the general population in China and California $[12,18]$. An abnormal ratio of CD4:CD8 cells $(<1.4)$ was present in all of the 15 hemodialysis patient, which was much higher than that in the general population (100 vs. $50 \%$ in the general population) [12]. These transient alterations in the numbers of peripheral blood leukocytes are similar to those seen in cases of seasonal influenza; Fas-Fas ligand signaling, which induces apoptosis, plays a major role in the mechanisms regulating the leukocyte population [19].

All the hemodialysis patients had abnormalities on chest radiography; unlike patients with the H1N1 virus in the general population in China [12], all the hemodialysis patients had severe pneumonia. All of the 15 hemodialysis patients infected with the 2009 pandemic influenza A ( $\mathrm{H} 1 \mathrm{~N} 1)$ virus were placed in respiratory isolation and were treated with a reduced dose of oseltamivir. There was some deterioration prior to the institution of mechanical ventilation. Six of the 15 patients developed respiratory failure requiring mechanical ventilation on days 7-9, and all these infections were complicated by $E$. coli nosocomial pneumonia. Because all of the 6 patients had no previous chronic lung diseases, the duration of mechanical ventilation in the 6 patients appeared very short (2-3 days). The median hospital length of stay of the 15 chronic hemodialysis patients was 14 days (range: 9-23 days). 
Uremia-induced immune dysfunction [20] might lead to this atypical presentation in dialysis patients. Hemodialysis patients are close to one another during their dialysis treatment, increasing their exposure to transmission of respiratory infection. After being diagnosed with $\mathrm{H} 1 \mathrm{~N} 1$ infection, all of the 15 patients were hemodialyzed in an isolated and separately ventilated area within the dialysis facility. The hemodialyzers were not reused. Both the hemodialysis patients with H1N1 infection and the dialysis unit staff wore gauze masks and hats. Fortunately, to date no H1N1 cases have been infected within our hemodialysis unit.

The current recommendations for the treatment of H1N1 influenza are oseltamivir or zanamivir [21]. Because oseltamivir is eliminated by the kidneys, a reduced dose of $75 \mathrm{mg}$ orally 3 times weekly after hemodialysis is recommended, although postdialysis dosing of $30 \mathrm{mg}$ daily has been shown to achieve adequate clinical exposure to the active form of the drug in hemodialysis patients [22]. These results were obtained from patients dialyzed on a low-flux dialyzer, therefore this dose may be insufficient when hemodiafiltration is used because of greater drug clearance. As the 15 hemodialysis patients were treated with hemodiafiltration because of congestive heart failure or left ventricle systolic function insufficiency, we administered an increased dose of $75 \mathrm{mg}$ dai- ly for 5 days. H1N1 influenza $\mathrm{A}$ is an important differential diagnosis in dialysis patients who are short of breath or febrile.

On the other hand, all of the 15 hemodialysis patients were finally discharged home. And all of the 462 general patients in China [12] also had a $0 \%$ hospital mortality, which was different from the experience of the 2009 pandemic influenza $A(\mathrm{H} 1 \mathrm{~N} 1)$ virus in other parts of the world [23-27]. This may suggest that the presentation seen in our country overall was of lesser severity.

In conclusion, the presentation and clinical course of the 2009 pandemic influenza A (H1N1) virus infection in chronic hemodialysis patients were atypical and relatively serious, which differed from the general population in China. Furthermore, these hemodialysis patients may have an extended period of viral shedding. It was important that H1N1 influenza pneumonia was highly suspected when the dialysis-dependent patients presented with cough and sputum only at the time of an H1N1 influenza pandemic.

\section{Disclosure Statement}

The authors have no potential conflicts of interest to be disclosed in this article.

\section{References}

1 Novel Swine-Origin Influenza A (H1N1) Virus Investigation Team: Emergence of a novel swine-origin influenza A (H1N1) virus in humans. N Engl J Med 2009;360:2605-2615.

-2 Trifonov V, Khiabanian H, Greenbaum B, Rabadan R: The origin of the recent swine influenza A (H1N1) virus infecting humans. Euro Surveill 2009;14:19193.

-3 Centers for Disease Control and Prevention: Update: drug susceptibility of swine-origin influenza A (H1N1) viruses, April 2009. MMWR Morb Mortal Wkly Rep 2009;58: 433-435.

-4 Centers for Disease Control and Prevention: Swine-origin influenza A (H1N1) virus infections in a school - New York City, April 2009. MMWR Morb Mortal Wkly Rep 2009; 58:470-472.

5 Centers for Disease Control and Prevention: Swine influenza A (H1N1) infection in two children - Southern California, MarchApril 2009. MMWR Morb Mortal Wkly Rep 2009;58:400-402.
-6 Centers for Disease Control and Prevention: Outbreak of swine-origin influenza A (H1N1) virus infection - Mexico, MarchApril 2009. MMWR Morb Mortal Wkly Rep 2009;58:467-470.

7 Centers for Disease Control and Prevention: Update: infections with a swine-origin influenza A (H1N1) virus - United States and other countries, April 28, 2009. MMWR Morb Mortal Wkly Rep 2009;58:431-433.

8 Naffakh N, van der Werf S: April 2009: an outbreak of swine-origin influenza A (H1N1) virus with evidence for human-tohuman transmission. Microbes Infect 2009; 11:725-728.

-9 Bin C, Xingwang L, Yuelong S, Nan J, Shijun C, Xiayuan X, et al: Clinical and epidemiologic characteristics of 3 early cases of influenza A pandemic (H1N1) virus 2009 infection, People's Republic of China, 2009. Emerg Infect Dis 2009;15:1418-1422.

10 World Health Organization: Influenza A (H1N1) - update 14. Geneva, World Health Organization, 2009. http://www.who.int/csr/ don/2009_05_04a/en/index.html (accessed November 30, 2009).
11 World Health Organization: CDC protocol of real-time RT-PCR for swine influenza A (H1N1). Geneva, World Health Organization, 2009. http://www.who.int/csr/resources/publications/swineflu/CDCrealtimeRTPCRprotocol_20090428.pdf (accessed November 30, 2009).

12 Bin C, Xing-Wang L, Yu M, Jian W, HongZhou L, Yu-Sheng C, et al: Clinical Features of the initial cases of 2009 pandemic influenza A (H1N1) virus infection in China. $\mathrm{N}$ Engl J Med 2009;361:2507-2517.

13 World Health Organization: Pandemic (H1N1) 2009: update 65. http://www.who. int/csr/don/2009_12_23/en/index.html (accessed December 23, 2009).

14 New influenza A (H1N1) virus: global epidemiological situation, June 2009 (in English, French). Wkly Epidemiol Rec 2009;84:249257.

15 Human infection with new influenza A (H1N1) virus: clinical observations from a school-associated outbreak in Kobe, Japan, May 2009 (in English, French). Wkly Epidemiol Rec 2009;84:237-244. 
16 Human infection with new influenza A (H1N1) virus: clinical observations from Mexico and other affected countries, May 2009 (in English, French). Wkly Epidemiol Rec 2009;84:185-189.

17 Centers for Disease Control and Prevention: Interim guidance for clinicians on identifying and caring for patients with swine-origin influenza A (H1N1) infection. http://www. cdc.gov/h1n1flu/identifyingpatients.htm (accessed September 16, 2009).

18 Centers for Disease Control and Prevention: Hospitalized patients with novel influenza A (H1N1) virus infection - California, AprilMay, 2009. MMWR Morb Mortal Wkly Rep 2009;58:536-541.

-19 Nichols JE, Niles JA, Boberts NJ Jr: Human lymphocyte apoptosis after exposure to influenza A virus. J Virol 2001;75:5921-5929.
20 Hauser AB, Stinghen AE, Kato S, Bucharles S, Aita C, Yuzawa Y, Pecoits-Filho R: Characteristics and causes of immune dysfunction related to uremia and dialysis. Perit Dial Int 2008;28(suppl 3):S183-S187.

21 Centers for Disease Control and Prevention: Updated interim recommendations for the use of antiviral medications in the treatment and prevention of influenza for the 20092010 season. http://www.cdc.gov/h1n1flu/ recommendations.htm (accessed September 16, 2009).

22 Robson R BA, Lynn K, Brewster M, Ward P: The pharmacokinetics and tolerability of oseltamivir suspension in patients on haemodialysis and continuous ambulatory peritoneal dialysis. Nephrol Dial Transplant 2006; 21:2556-2562.
23 Louie JK, Acosta M, Winter K, et al: Factors associated with death or hospitalization due to pandemic 2009 influenza A (H1N1) infection in California. JAMA 2009;302:18961902.

24 Jain S, Kamimoto L, Bramley AM, et al: Hospitalized patients with $2009 \mathrm{H} 1 \mathrm{~N} 1$ influenza in the United States, April-June 2009. N Engl J Med 2009;361:1935-1944.

-25 Domínguez-Cherit G, Lapinsky SE, Macias AE, et al: Critically ill patients with 2009 influenza A (H1N1) in Mexico. JAMA 2009; 302:1880-1887.

26 ANZIC Influenza Investigators: Critical care services and $2009 \mathrm{H} 1 \mathrm{N1}$ influenza in Australia and New Zealand. N Engl J Med 2009; 361:1925-1934.

-27 Kumar A, Zarychanski R, Pinto R, et al: Critically ill patients with 2009 influenza A (H1N1) infection in Canada. JAMA 2009; 302:1872-1879. 